\title{
Evolution and Assessment of the Atmospheric Composition in Hangzhou and its Surrounding Areas during the G20 Summit
}

\author{
Kai Wu ${ }^{1,2}$, Ping Kang1*, Xin Tie ${ }^{3}$, Shan $\mathrm{Gu}^{4}$, Xiaoling Zhang ${ }^{1}$, Xiaohang Wen ${ }^{1}$, Lingkai Kong, \\ Sihui Wang, Yuzi Chen ${ }^{6}$, Weihao Pan ${ }^{1}$, Zhanshan Wang ${ }^{7 *}$ \\ ${ }^{1}$ Plateau Atmosphere and Environment Key Laboratory of Sichuan Province, School of Atmospheric Sciences, Chengdu \\ University of Information Technology, Chengdu 610225, China \\ ${ }^{2}$ Department of Land, Air, and Water Resources, University of California, Davis, CA 95616, USA \\ ${ }^{3}$ Department of Earth and Environmental Sciences, University of Rochester, NY 14620, USA \\ ${ }^{4}$ Department of Ecology and Evolutionary Biology, University of California, Irvine, CA 92617, USA \\ ${ }^{5}$ Chunan Meteorological Bureau, Hangzhou 310007, China \\ ${ }^{6}$ Nanjing University of Information Science and Technology, Nanjing 210044, China \\ ${ }^{7}$ State Key Laboratory of Environmental Criteria and Risk Assessment, Chinese Research Academy of Environmental \\ Sciences, Beijing 100012, China
}

\begin{abstract}
To evaluate the effectiveness of control strategies during the G20 Summit (August 24-September 6, 2016), five sites were selected for investigating the variation in air pollution in the city of Hangzhou and its surrounding areas. The results showed that the air quality in Hangzhou greatly improved after the implementation of strict emission controls. Compared to the same dates from the five preceding years, the G20 period exhibited low relative humidity during the early stage (August 27-31) and no significant differences in other meteorological conditions. The $\mathrm{SO}_{2}, \mathrm{NO}_{2}, \mathrm{PM}_{10}$, and $\mathrm{PM}_{2.5}$ concentrations averaged across the five sites in Hangzhou decreased by $42.6 \%, 57.1 \%, 36 \%$, and $38.5 \%$, respectively, although the average $\mathrm{O}_{3}$ concentration increased by $19 \%$. These changes indicate that the emission reduction measures decreased the concentrations of several pollutants. Compared to the same dates from the previous year (August 24-September 6, 2015), the G20 period

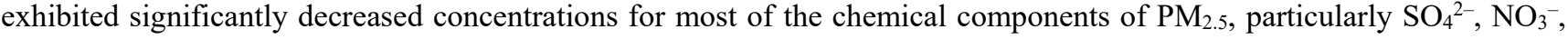
and $\mathrm{NH}_{4}{ }^{+}$. Additionally, the aerosol optical depth (AOD) and the $\mathrm{NO}_{2}$ column densities were found to exhibit similar trends with that of the pollutants in this city.
\end{abstract}

Keywords: Air quality; Emission reduction; G20 Summit; Ozone sensitivity.

\section{INTRODUCTION}

Characterized by fine particles $\left(\mathrm{PM}_{2.5}\right)$, nitrogen oxides $\left(\mathrm{NO}_{\mathrm{x}}\right)$, and ozone $\left(\mathrm{O}_{3}\right)$, regional air pollution has been increasingly prominent in China in recent years due to the rapid development of urbanization and industrialization (Chan and Yao, 2008). Air pollutants such as $\mathrm{PM}_{2.5}$ and ozone have significant impacts on public health and have been estimated to cause millions of premature deaths per year worldwide (Cohen et al., 2017). Extensive studies have been conducted through observational, modeling, and longterm data analyses to investigate the sources, evolution, and formation mechanisms of air pollution in China; however,

\footnotetext{
${ }^{*}$ Corresponding author.

E-mail address: kangping@cuit.edu.cn (P. Kang); qingkongweilan@tom.com (Z. Wang)
}

there are still many uncertainties remaining (Jin et al., 2015; $\mathrm{Hu}$ et al., 2016). Therefore, greater insights are required to generate evidence-based emission control policies. Air pollution in the Beijing-Tianjin-Hebei (BTH), Yangtze River Delta (YRD), Pearl River Delta (PRD), and Sichuan Basin (SCB) regions have been reported to be the most severe in China (Hu et al., 2017). Strict short-term emission controls have effectively improved the air quality during several special events such as the Beijing Olympics in 2008, the Asia-Pacific Economic Cooperation (APEC) meeting in November 2014, the Nanjing Youth Olympic Games in 2014, and the China Victory Day Parade in 2015. These short-term emission controls provide an ideal opportunity for evaluating our current understanding of the formation mechanisms of air pollution and exploring the impact of alternative control options to aid in the formulation of more effective policies for emission reduction.

Hangzhou, which is located in the southern YRD region, is the capital of Zhejiang Province and a typical megacity 
that covers an area of about $16,596 \mathrm{~km}^{2}$ and has a population of more than 9.18 million residents. The air pollution in Hangzhou has become more serious in recent years due to substantial local emissions and regional transport of air pollutants (Dong et al., 2013; Liu et al., 2015). Jansen et al. (2014) reported that the contribution of secondary inorganic aerosol to $\mathrm{PM}_{2.5}$ concentration has reached approximately $50 \%$ during haze episodes. Li et al. (2018) found that the secondary transformation of organic aerosols are the main sources of particle matter. In addition to local emissions, transboundary aerosol and trace gases transport also contributes to the severe air pollution in Hangzhou (Zhang et al., 2018). The G20 Summit, which was held in Hangzhou from September 4 to 5 in 2016, provides an ideal opportunity for evaluating the effectiveness of emission reduction measures in the YRD region. To improve the air quality during the G20 Summit, the Zhejiang Summit Environmental Protection Plan (ZSEPP) was implemented by the Zhejiang provincial government from August 24 to September 6, 2016. In this plan, strict air pollution alleviation measures were adopted to reduce the emissions of air pollutants in Hangzhou and its surrounding cities. Considering the contribution of regional transport, the emission control strategy was extended to the surrounding areas of Hangzhou (e.g., Huzhou, Jiaxing, Jinhua, and Shaoxing).

A number of previous studies investigated the effect of emission controls during the G20 Summit by using surface observations and numerical models (Feng et al., 2019; Ni et al., 2019). Ji et al. (2018) analyzed the effects of regional transport and emission control on the formation of fine particles during the G20 Summit and found that the suppression of daytime peak secondary organic carbon (SOC) formation was the major reason for the decreased particle matter concentration. Su et al. (2017) utilized ozone lidar and vertical column densities (VCDs) of ozone for exploring ozone variation during the G20 Summit and reported that meteorological conditions dominated the variations of ozone concentration. However, these studies mainly focused on single pollutants such as $\mathrm{PM}_{2.5}$ or ozone while the overall variation of air pollutants during the G20 Summit remains unclear and should be explored further.

In this study, the meteorological conditions, concentrations of six criteria air pollutants $\left(\mathrm{PM}_{2.5}, \mathrm{PM}_{10}, \mathrm{O}_{3}, \mathrm{NO}_{2}, \mathrm{SO}_{2}\right.$, and $\mathrm{CO})$, chemical composition of $\mathrm{PM}_{2.5}$, aerosol optical depth (AOD), and $\mathrm{NO}_{2}$ column data retrieved by satellite in Hangzhou before, during, and after the 2016 G20 Summit were analyzed for accurately assessing the contributions of the safeguard measures implemented during the G20 Summit to improve air quality. This paper is organized as follows. We first analyzed the daily average pollutant concentrations during the G20 period. Then we investigated the effect of meteorological conditions, diurnal variations, and the components on reducing air pollution by comparing the pollutant concentrations during days with stable meteorological conditions. Finally, we compared the emission reduction measures implemented for the G20 Summit with that of previous events to comprehensively evaluate the pollution control strategies implemented for the G20 Summit.

\section{METHODS}

\section{Study Domain}

Through the collaboration with surrounding cities, regional control levels were divided into three types (i.e., the core area, strictly controlled area, and controlled area), which were classified by their respective distances to the central main court (50 km, $100 \mathrm{~km}$, and $300 \mathrm{~km}$, as shown in Fig. 1). Of these three areas, the core area included Hangzhou (HangZ), Huzhou (HuZ), Jiaxing (JX), and Shaoxing (SX); the strictly controlled area included Ningbo (NB), Jinhua (JH), and Quzhou (QZ); and the control area included Wenzhou (WZ), Zhoushan (ZS), Taizhou (TZ), and Lishui (LS).

\section{Measurements of Air Pollutants}

In this study, the concentrations and variation characteristics of six air pollutants as well as the corresponding meteorological conditions during the G20 period were compared with those observed during the same period from 2011 to 2015 to explore the change in air quality in different situations (i.e., with vs. without the air quality improvement contributions of the safeguard measures). In addition, monitoring data of six air pollutants were collected from five sites in Hangzhou (Table 1 and Fig. 1), including Xiasha (XS; a regional site), Linping (LP; a suburban site), Xixi (XX; a background site), Zhaohui ( $\mathrm{ZH}$; a traffic pollution site), and Hemu (HM; an urban site). The method of observing air pollutants from 2011 to 2015 is the same as that monitored in the G20 Summit.

At these five sites, a TEOM 1405-D double-channel air particulate monitor by Rupprecht \& Patashnick Co. was used to monitor $\mathrm{PM}_{2.5}$. The aerosol passed through a $\mathrm{PM}_{2.5}$ cyclone; then, the $\mathrm{PM}_{2.5}$ particles in the ambient air were constantly inhaled to the internal region by the sampling cutter. Finally, a filter dynamic measurement system (FDMS) and a tapered element oscillating microbalance (TEOM) were utilized to measure the $\mathrm{PM}_{2.5}$ concentration. A Thermo Fisher 1400 monitor was used to monitor $\mathrm{PM}_{10}$ using the TEOM method. A $49 i$ ultraviolet spectrophotometry $\mathrm{O}_{3}$ analyzer produced by Thermo Electron Corp. in the United States was used for $\mathrm{O}_{3}$ observations, and it has a minimum detection limit of $2.0 \mu \mathrm{g} \mathrm{m}^{-3}$, a zero drift of less than $2.0 \mu \mathrm{g} \mathrm{m}^{-3}$ day $^{-1}$, and a span drift of less than $\pm 1 \%$ day $^{-1}$. A Model $300 \mathrm{E}$ gas filter correlation analyzer was used as the $\mathrm{CO}$ analyzer, with a minimum detection limit of $1.0 \mu \mathrm{g} \mathrm{m}^{-3}$, a zero drift of less than $2.0 \mu \mathrm{g} \mathrm{m}^{-3}$ day $^{-1}$, and a cross drift of $\pm 1 \%$ day $^{-1}$. The sampling and observations of $\mathrm{NO}_{\mathrm{x}}$ were performed using a Model 400E NO- $\mathrm{NO}_{2}-\mathrm{NO}_{\mathrm{x}}$ analyzer. This instrument measures the fluorescence of the excited-state $\mathrm{NO}_{2}$ produced from the chemical reaction of $\mathrm{NO}$ and $\mathrm{O}_{3}$ to obtain the ambient NO concentration. There is a linear positive correlation between the intensity of the emitted light and the volume fraction of $\mathrm{NO}$. While detecting $\mathrm{NO}_{2}$, the $\mathrm{NO}_{2}$ is converted to NO through a molybdenum converter, and then the quantitative analysis is conducted using chemiluminescence reactions. This converter has a minimum detection limit of 5 $\times 10^{-3} \mu \mathrm{g} \mathrm{m}^{-3}$, a zero drift of less than $2.5 \times 10^{-3} \mu \mathrm{g} \mathrm{m}^{-3}$ day $^{-1}$, and a full drift of $\pm 1 \%$ day $^{-1}$. All of the instruments collected data $24 \mathrm{~h}$ per day, and the data were read every 5 minutes. The accuracy of the observation data was ensured by the 

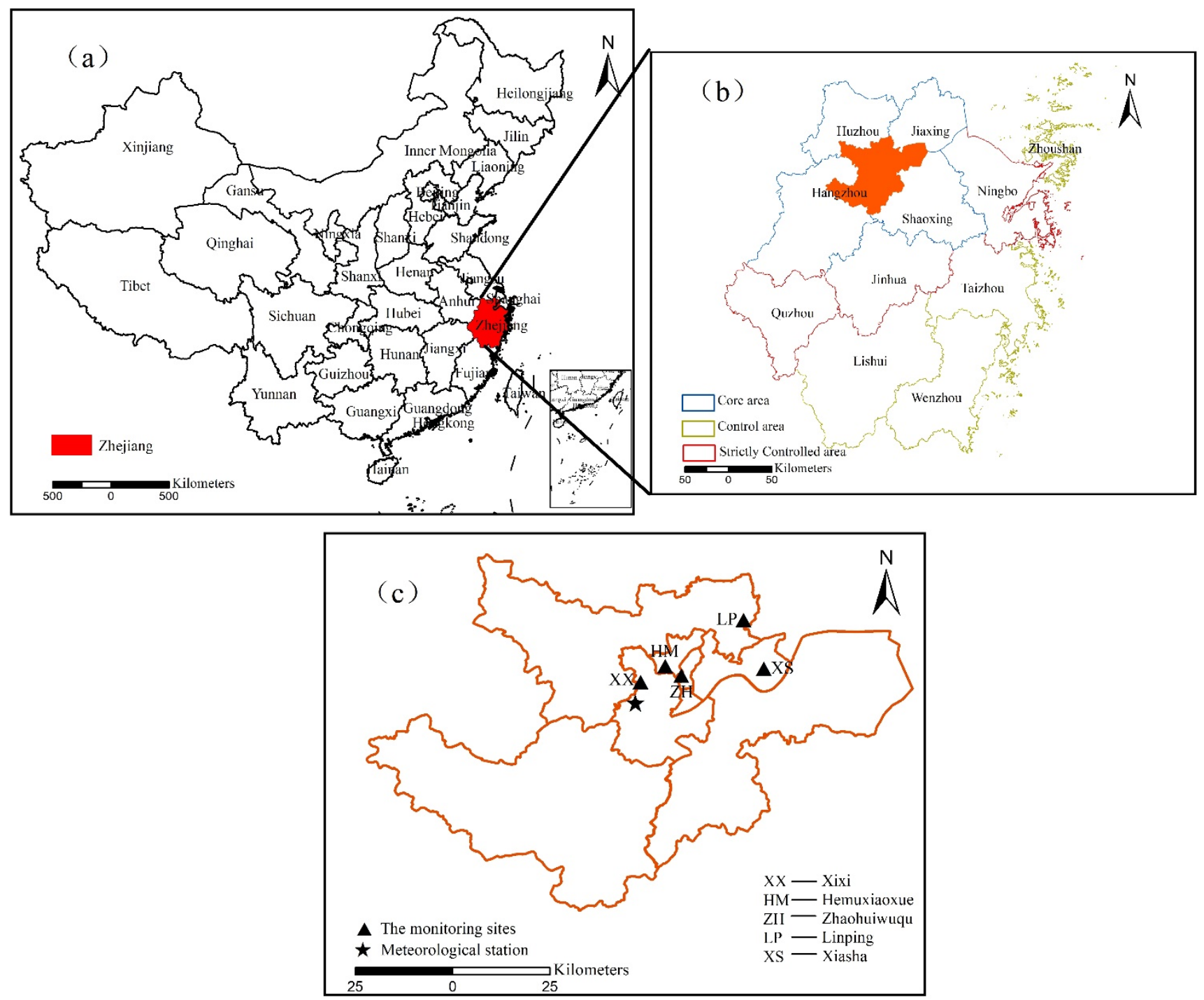

Fig. 1. Location of the study area and air quality monitoring sites in Hangzhou. (a) Location of Zhejiang Province. (b) Locations of cities in Zhejiang Province. (c) Central urban area of Hangzhou.

Table 1. Information about air pollutant monitoring sites and meteorological station.

\begin{tabular}{llll}
\hline Monitoring site & Abbreviation & Location & Type \\
\hline Xiasha site & $\mathrm{XS}$ & $30.31^{\circ} \mathrm{N}, 120.32^{\circ} \mathrm{E}$ & Regional \\
Linping site & $\mathrm{LP}$ & $30.41^{\circ} \mathrm{N}, 120.30^{\circ} \mathrm{E}$ & Suburban \\
Xixi site & $\mathrm{XX}$ & $30.27^{\circ} \mathrm{N}, 120.10^{\circ} \mathrm{E}$ & Background \\
Zhaohui site & $\mathrm{ZH}$ & $30.29^{\circ} \mathrm{N}, 120.16^{\circ} \mathrm{E}$ & Traffic pollution \\
Hemu site & $\mathrm{HM}$ & $30.31^{\circ} \mathrm{N}, 120.12^{\circ} \mathrm{E}$ & Urban \\
$\mathrm{PM}_{2.5}$ chemical composition collector & $\backslash$ & $30.26^{\circ} \mathrm{N}, 120.10^{\circ} \mathrm{E}$ & Background \\
Meteorological station & $\mathrm{I}$ & $30.26^{\circ} \mathrm{N}, 120.10^{\circ} \mathrm{E}$ & Background \\
\hline
\end{tabular}

regular inspection of the zero point, full range, and precision of the instruments.

\section{Meteorological Data}

The meteorological data were obtained from the China Meteorological Station Data Sharing Service System (http://cdc.cma.gov.cn/home.do). The meteorological parameters were monitored at the Hangzhou meteorological station, which is located near the Xixi monitoring site, and these parameters consisted of temperature $(\mathrm{T})$, relative humidity (RH), sunshine duration (SD), solar radiation (SR), wind direction (WD), wind speed (WS), sea-level pressure (P), and precipitation (PREC).

\section{Analysis of the PM2.5 Chemical Composition}

The chemical composition of $\mathrm{PM}_{2.5}$ was measured at the 
Hangzhou meteorological station (as shown in Fig. 1), which is located on the roof of a four-story building, approximately $20 \mathrm{~m}$ above the ground and approximately $800 \mathrm{~m}$ south of the Xixi monitoring site. We used an electronic balance to weigh the Teflon filters before and after sampling to obtain the daily average $\mathrm{PM}_{2.5}$ mass concentrations. The detection limit is $10 \mu \mathrm{g}(\mathrm{AX} 105 \mathrm{DR})$ in a superclean lab (T: $20 \pm 1{ }^{\circ} \mathrm{C}$; $\mathrm{RH}: 40 \pm 3 \%)$. Then, an online analyzer for the monitoring of aerosols (ADI 2080 MARGA; Applikon-ECN, Netherlands) was used to measure the water-soluble ions and trace elements in $\mathrm{PM}_{2.5}$. A wet rotating denuder was used in the MARGA samples to allow gases to absorb on the wall of a liquid-coated annulus through which particles pass. A supersaturation treatment method was used in the steam-jet aerosol collector where the particles ultimately arrive. Droplets form due to the condensation of steam and can then be collected. The detection limits of major ions, $\mathrm{Cl}^{-}, \mathrm{NO}_{3}{ }^{-}, \mathrm{SO}_{4}{ }^{2-}, \mathrm{NH}_{4}{ }^{+}, \mathrm{Na}^{+}$, $\mathrm{K}^{+}, \mathrm{Mg}^{2+}$, and $\mathrm{Ca}^{2+}$, were 0.008, 0.005, 0.007, 0.040, 0.070, $0.050,0.013$, and $0.030 \mu \mathrm{g} \mathrm{m}^{-3}$, respectively. We used a syringe system to collect both gases and aerosols and analyzed them via ion chromatography, which provided hourly results. The $R^{2}$ values of the calibration curves for the concentrations of ions and elements exceeded 0.999 .

\section{MODIS Aerosol and OMI NO $\mathrm{O}_{2}$ Column Data Set}

The Moderate Resolution Imaging Spectroradiometer (MODIS) is carried on the Terra and Aqua satellites (Jin and Holloway, 2015). MODIS scans Hangzhou twice per day (10:30 and 13:30 BJT), and the recently released MODIS AOD product (Level 3 version 5) was applied to this study (http://modis-atmos.gsfc.nasa.gov/). The AOD is obtained by the $0.47 \mu \mathrm{m}$ and $0.66 \mu \mathrm{m}$ spectral channels and interpolated to the $0.55 \mu \mathrm{m}$ channel. These MODIS AOD results include multiple AOD pixels covering the spatial scale of $0.5^{\circ} \times 0.5^{\circ}$ and centered on Hangzhou (i.e., $30^{\circ} \mathrm{N}, 120^{\circ} \mathrm{E}$ ). The total density of the $\mathrm{NO}_{2}$ column in Hangzhou was derived from the Ozone Monitoring Instrument (OMI; which passes Hangzhou once per day, i.e., near 13:30 BJT) at a $0.25^{\circ} \times$ $0.25^{\circ}$ resolution. The uncertainty in the $\mathrm{NO}_{2}$ column density per pixel was estimated to be $\pm 0.5-1.5 \times 10^{15}$ molecules $\mathrm{cm}^{-2}$ with a relative error between $10 \%$ and $40 \%$.

\section{RESULTS AND DISCUSSION}

\section{Analysis of Daily Average Pollutant Concentrations during the G20 Period}

Fig. 2 shows a comparison of the daily average concentrations of six air pollutants during the G20 period (2016) and those during the same period in the past three years (2013-2015). It can be seen that the concentrations of $\mathrm{SO}_{2}, \mathrm{NO}_{2}, \mathrm{CO}, \mathrm{PM}_{10}$, and $\mathrm{PM}_{2.5}$ decreased significantly during the $\mathrm{G} 20$ period. The $\mathrm{NO}_{2}$ concentrations of the five sites decreased by $43.9-70.5 \%$, with an average of $57.1 \%$, which was the largest of the five air pollutants. And the $\mathrm{SO}_{2}$ concentrations of the five sites declined by $17.5-56.6 \%$ (with an average of $42.6 \%$ ). The $\mathrm{PM}_{2.5}$ and $\mathrm{PM}_{10}$ concentration decreased by $34.5-42 \%$ (with an average of $38.5 \%$ ) and $30.1-46.4 \%$ (with an average of $36.0 \%$ ), respectively.

Notably, the $\mathrm{O}_{3}$ concentration in Hangzhou increased significantly during the G20 period. The average increase of $\mathrm{O}_{3}$ at the five sites was $19 \%$, especially the XX site reached $48.7 \%$. This phenomenon may correspond to the $\mathrm{O}_{3}-\mathrm{NO}_{\mathrm{x}}-$ VOCs sensitivity. Yan et al. (2016) utilized the WRF-CMAQ model to analyze the $\mathrm{O}_{3}$ formation in the YRD region and found that the sensitivity pattern of $\mathrm{O}_{3}$ formation in Hangzhou was VOCs-limited. In these areas, if $\mathrm{NO}_{\mathrm{x}}$ emissions are reduced, the $\mathrm{O}_{3}$ concentration will first increase and then decrease. Therefore, the possible reason for the increase in $\mathrm{O}_{3}$ concentration during the G20 period in 2016 is that the $\mathrm{NO}_{\mathrm{x}}$ emission control measures were stronger than the VOCs emission control measures, which resulted in the weak inhibition of $\mathrm{NO}_{x}$ on $\mathrm{O}_{3}$ production and significant increase of $\mathrm{O}_{3}$ concentrations (Xing et al., 2011; Yarwood et al., 2013). In addition, biogenic VOC (BVOC) emissions also play an essential role in $\mathrm{O}_{3}$ formation because they are highly reactive hydrocarbons that cause the rapid increase of $\mathrm{O}_{3}$ when oxidized by hydroxyl radicals (Geng et al., 2011; Situ et al., 2014). Using the MEGAN model, Liu et al. (2018) estimated biogenic emissions at $18.86 \times 10^{5}$ ton $\mathrm{yr}^{-1}$ over the YRD region with higher emissions observed in Hangzhou and surrounding areas. Wu et al. (2019) employed the WRF-CMAQ model to investigate the effects of BVOC emissions on ozone formation over China and pointed out that the high BVOC emissions across eastern China increased the surface ozone levels, particularly in the YRD regions. During the G20 Summit, the $\mathrm{T}$ reached $31^{\circ} \mathrm{C}$, and such a high $\mathrm{T}$ is beneficial to the emission of large amounts of BVOC. Therefore, BVOC emissions may also have significant contributions to the increased $\mathrm{O}_{3}$ concentrations observed during the G20 period.

\section{Meteorological Conditions}

Fig. S1 presents the daily averages of the meteorological parameters (e.g., T, RH, P, and WS) during the G20 period and the same time period in the previous five years. In general, the RH during the G20 period was low in the early stage compared with the previous five years, and the T, P and WS did not show significant differences. In addition, we compared the meteorological parameters during the G20 period with those before and after the period (as shown in Table 2). The average $\mathrm{T}$ was highest before the $\mathrm{G} 20$ period, reaching up to $33.2 \pm 1.8^{\circ} \mathrm{C}$. The average $\mathrm{RH}$ and $\mathrm{P}$ during the G20 period were similar to those before the G20 period. The WS, SD, and SR were slightly higher during the G20 period than those before and after the G20 period.

To further investigate the impacts of meteorological conditions on changes in pollutant concentrations during the G20 period, the variations in surface meteorological parameters and their relationships with air pollutants were analyzed. According to the intensity of the emission reductions and joint control strategies over Hangzhou and surrounding areas, we divided the whole period into three stages. S1 (August 24-27) was the starting stage with industrial and construction emission control. During S2 (August 28-31), there was traffic restrictions added to the emission control strategy. And S3 (September 1-6) was the G20 Summit period, which was the strictest emission control stage. In the $\mathrm{S} 1$ stage, the concentrations of all pollutants (except $\mathrm{O}_{3}$ ) 

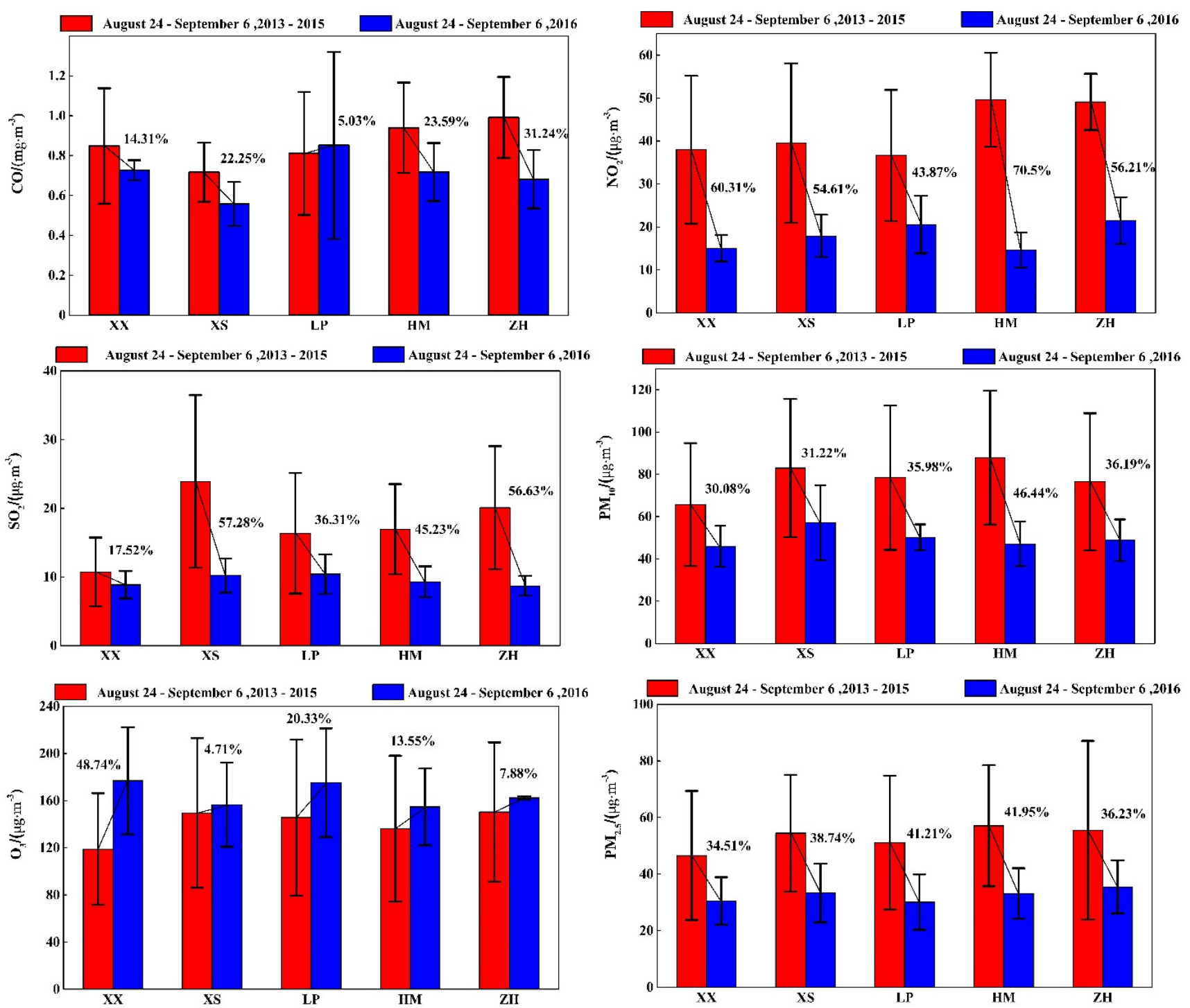

Fig. 2. Daily average concentrations of six air pollutants at different sites during the G20 period of 2016 and during the same period in the previous three years (2013-2015).

Table 2. Comparison of average values of meteorological parameters before, during, and after the G20 period from Aug. to Sep. 2016.

\begin{tabular}{lllllll}
\hline Period & T & P & RH & WS & SD & SR \\
\hline Before G20 (Aug. 10-23) & $33.2 \pm 0.8$ & $999.3 \pm 1.8$ & $71.8 \pm 0.3$ & $2.1 \pm 0.4$ & $7.8 \pm 3.1$ & $15.7 \pm 3.3$ \\
During G20 (Aug. 24-Sep. 6) & $31.0 \pm 1.9$ & $1002.2 \pm 2.8$ & $69.9 \pm 1.4$ & $2.7 \pm 0.6$ & $7.9 \pm 3.6$ & $16.2 \pm 5.4$ \\
After G20 (Sep. 7-20) & $23.7 \pm 1.5$ & $1007.3 \pm 3.3$ & $79.8 \pm 1.0$ & $2.5 \pm 0.9$ & $6.4 \pm 3.1$ & $14.6 \pm 5.5$ \\
\hline
\end{tabular}

decreased. Compared with the $\mathrm{NO}_{2}$ and $\mathrm{PM}_{2.5}$ concentrations on August 24, the average concentration of $\mathrm{NO}_{2}$ and $\mathrm{PM}_{2.5}$ during S1 decreased by $19.9 \%$ and $6.8 \%$, respectively. This occurred because construction sites temporarily stopped production and the meteorological conditions (i.e., easterly wind) were conducive to the dilution and removal of various pollutants. As shown in Fig. 3, with the effect of high pressure (see Fig. S2 in Supporting Information), the weather in Hangzhou was fair, with an average maximum $\mathrm{T}$ of $33.8^{\circ} \mathrm{C}$ over the four days. The maximum $\mathrm{T}$ on August 25 was $35.5^{\circ} \mathrm{C}$, and the SD reached up to $11.6 \mathrm{~h}$, which was the maximum for the entire study period. Under the influence of strong radiation, the maximum 8-h daily average of $\mathrm{O}_{3}$ on August 25 was $208 \mu \mathrm{g} \mathrm{m}^{-3}$ (i.e., the peak value during the study period). The average WS at $10 \mathrm{~m}$ was $2.9 \mathrm{~m} \mathrm{~s}^{-1}$, and the dominant wind direction was easterly (the frequency of east-northeasterly, easterly, and east-southeasterly winds was $39.6 \%)$. With the effect of cold air on the night of August 26 (see Fig. S3), there were significant wind (the average WS at $10 \mathrm{~m}$ increased to $3.7 \mathrm{~m} \mathrm{~s}^{-1}$ ), cooling ( $\mathrm{T}$ decreased by approximately $\left.3^{\circ} \mathrm{C}\right)$, and PREC $(14.6 \mathrm{~mm})$ processes in Hangzhou. 

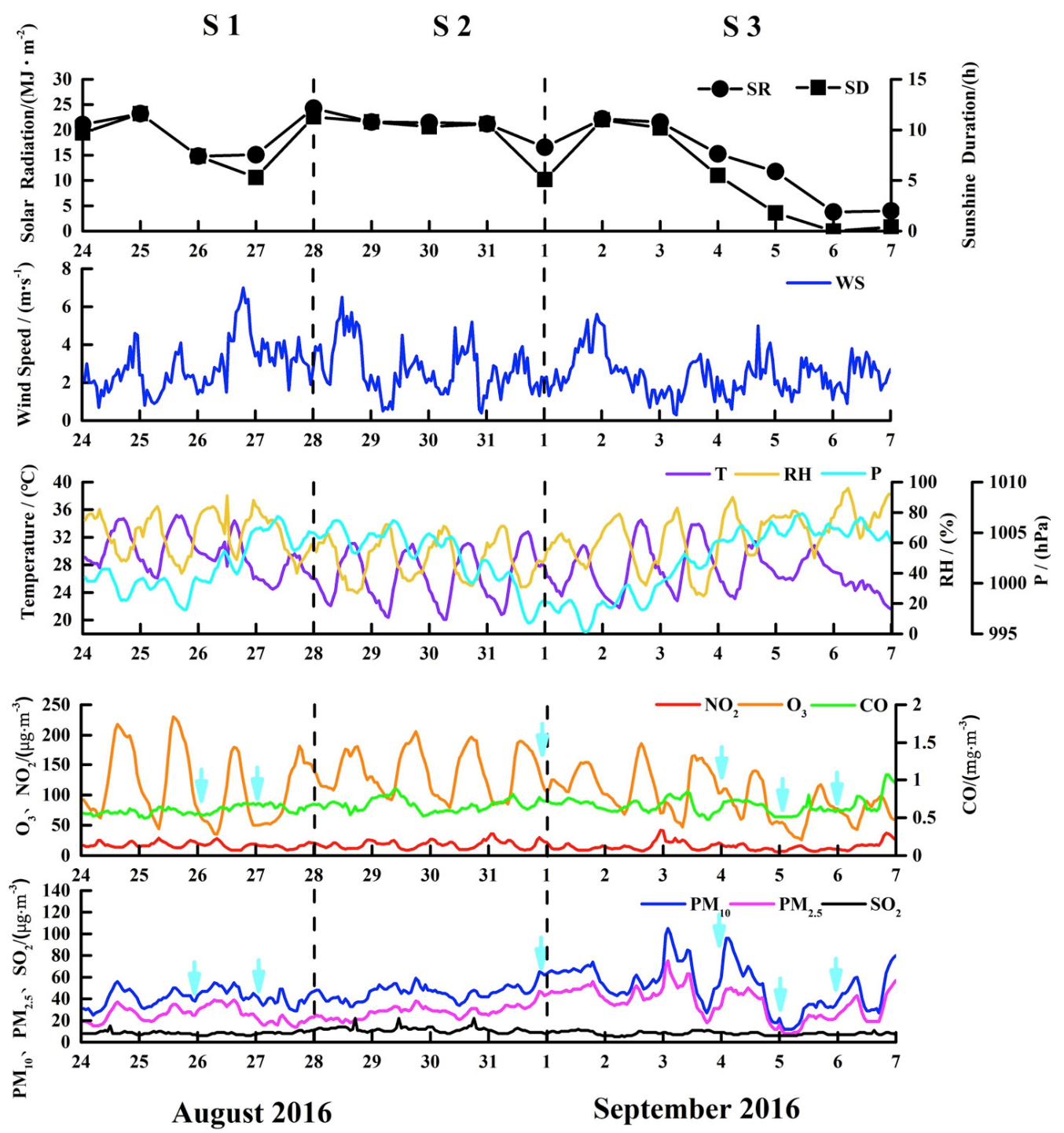

Fig. 3. Solar radiation (SR), sunshine duration (SD), wind speed (WS), temperature (T), relative humidity (RH), pressure (P), and hourly concentrations of six air pollutants at the XX site from August 24 to September 6, 2016. Blue arrows indicate precipitation.

In $\mathrm{S} 2$, under the influence of static weather and regional transport of air pollutants, the concentrations of various pollutants in Hangzhou reached peak values before and after August 29 (Ji et al., 2018). During this stage, the WD in Hangzhou transformed from northwesterly to westerly winds and then to southwesterly winds. On August 28, Hangzhou experienced strong northwesterly winds, with the daily average WS reaching $3.9 \mathrm{~m} \mathrm{~s}^{-1}$ (the peak value during the study period). Influenced by the cold northwesterly winds, the pollutant concentrations increased compared with those observed on August 27 because of upstream pollutant transport, while the $\mathrm{RH}$ decreased to $45.6 \%$ (the minimum value during the study period). From August 29 to 31, the weather condition was constant, with a low planet boundary layer at night accompanied by low WS (with an average value of $2.3 \mathrm{~m} \mathrm{~s}^{-1}$ ), which were unfavorable to the diffusion of pollutants. In addition, PREC was not observed in Hangzhou during this period, which had an average maximum $\mathrm{T}$ of $32^{\circ} \mathrm{C}$ and daily average SD of $10.75 \mathrm{~h}$. These findings revealed that the radiation condition was good and the diffusion capacity was weak, which was beneficial for the formation and accumulation of $\mathrm{O}_{3}$ from photochemical reactions. Compared with the $\mathrm{S} 1$ stage, the $\mathrm{SO}_{2}$ concentration had the largest increase of $30.5 \%$ and reached $12.0 \mu \mathrm{g} \mathrm{m}^{-3}$ on August 28 and 29. Because the coal combustion control measures in this stage were maintained or more strictly controlled, the $30.5 \%$ increase should be considered a reflection of the contribution of regional transported pollutants to the air pollution level in Hangzhou (see Table S2).

During S3, a dramatic weather change occurred with many cloud systems. The daily average SD was $5.6 \mathrm{~h}$, a decrease of $47.9 \%$ compared with that in the S2 which meant that photochemical consumption of $\mathrm{O}_{3}$ precursors might be weakened on these days. And the average WS was $3.3 \mathrm{~m} \mathrm{~s}^{-1}$ on September 1 which was beneficial to the transmission of pollutants. The warm southwest flow that entered Hangzhou 
had higher aerosol loading, which could have originated an aged air mass with secondary particle growth (Ji et al., 2018). Then the $\mathrm{PM}_{2.5}$ and $\mathrm{PM}_{10}$ concentrations reached their peak values due to the unexpected increases of secondary aerosol components during this period. On September 2-3, northwesterly flow following the passage of a trough dominated, with a low pressure field (see Fig. S4) with an average WS of $2.1 \mathrm{~m} \mathrm{~s}^{-1}$. There was no PREC over 3 continuous days, which was not conducive to the diffusion and removal of pollutants. On September 4-6, persistent easterly winds with weak PREC occurred in Hangzhou, and these conditions had a wet scavenging effect on pollutants. The concentrations of $\mathrm{PM}_{2.5}, \mathrm{PM}_{10}, \mathrm{NO}_{2}$, and $\mathrm{CO}$ were lowest on September 5. In this stage, the total PREC, average $\mathrm{RH}$, and average T were $2.3 \mathrm{~mm}, 65 \%$, and $31^{\circ} \mathrm{C}$, respectively. With high cloud coverage and low radiation at this time, the formation and accumulation of $\mathrm{O}_{3}$ from photochemical reactions were suppressed. The stable weather was beneficial for the accumulation of particles, and the humidity (65\%) was greatly increased compared with that during S2 (50\%). High-humidity conditions may have promoted the formation of sulfate and further increased the concentration of $\mathrm{PM}_{2.5}$ (by $33.2 \%$ ) and $\mathrm{PM}_{10}$ (by $21.5 \%$ ). However, the pollutant concentrations on September 5, when the G20 Summit was held in Hangzhou, were significantly lower than those during the entire period due to the strict control measures.

\section{Characteristics of Diurnal Variations in Pollutants during G20}

The diurnal variations of $\mathrm{SO}_{2}, \mathrm{CO}, \mathrm{NO}_{2}, \mathrm{O}_{3}, \mathrm{PM}_{10}$, and $\mathrm{PM}_{2.5}$ during the $\mathrm{G} 20$ period were compared with the same time period in 2015 (following the named non-G20 period, August 24-September 6, 2015), as shown in Fig. 4. The diurnal variations of $\mathrm{PM}_{2.5}, \mathrm{PM}_{10}, \mathrm{SO}_{2}, \mathrm{NO}_{2}$, and $\mathrm{CO}$ during

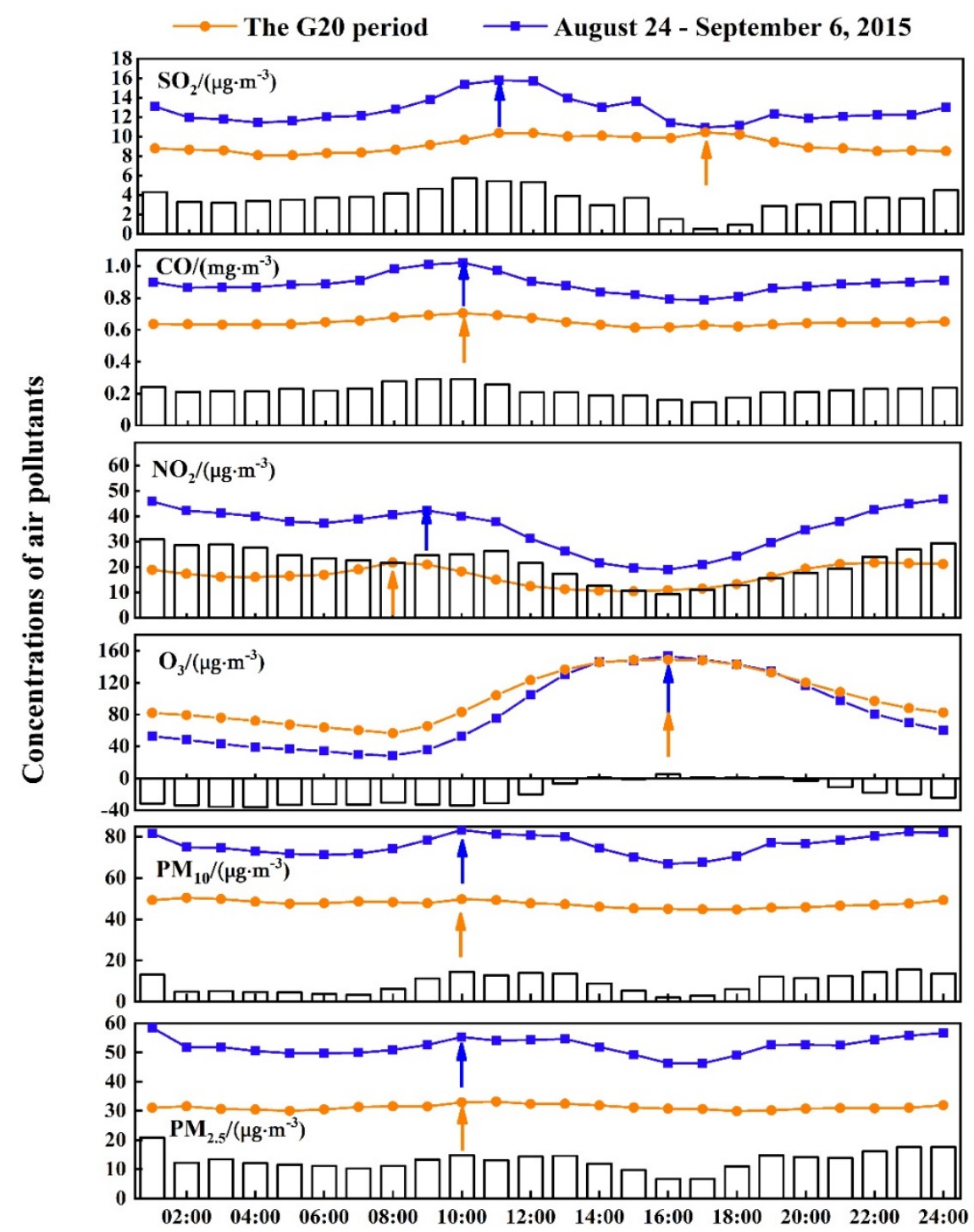

Fig. 4. Characteristics of diurnal variations in six air pollutants at the XX site during the G20 period (August 24-September 6, 2016) and the non-G20 period (August 24-September 6, 2015). The bars at the bottom of each panel represent the concentrations of pollutants in the G20 period minus the concentrations of pollutants in the non-G20 period. (Note: The arrows denote the max value) 
the G20 period were significantly lower than the non-G20 period. The $\mathrm{O}_{3}$ showed a single peak maximum at 16:00 local time which related to atmospheric photochemical reactions near the surface. Diurnal variation of $\mathrm{PM}_{2.5}$ and $\mathrm{PM}_{10}$ were similar in these two periods with high concentrations in the morning due to the traffic source emissions. And the concentration of $\mathrm{SO}_{2}$ exhibited a single-peak curve, and the peak appeared at 11:00. The strong vertical diffusion may have essential contribution on high $\mathrm{SO}_{2}$ during daytime while the low concentration at night may correspond to the wet deposition of $\mathrm{SO}_{2}$ from PREC events and dry deposition (Quan and Zhang, 2008). Diurnal variations of $\mathrm{NO}_{2}$ and $\mathrm{CO}$ showed a less obvious bimodal diurnal change. During the rush hours in the late afternoon, the concentration of $\mathrm{NO}_{2}$ began to increase until the following second peak appeared at 01:00 the next day. The second peak may be related to the decreased boundary layer height at night then impact the diffusion of pollutants.

In addition, it can be found that there were some similar patterns of air pollutants. The diurnal variation of $\mathrm{PM}_{2.5}$ was highly correlated with $\mathrm{PM}_{10}$, which is possibly because the ratios of $\mathrm{PM}_{2.5}$ to $\mathrm{PM}_{10}$ were high (0.64-0.92) (as shown in Fig. 4). And this phenomenon may also suggest that they may have the same potential sources ( $\mathrm{Xu}$ et al., 2018). As $\mathrm{NO}_{2}$ and $\mathrm{SO}_{2}$ are both precursors for particle matter through secondary inorganic aerosol (SIA) formation, $\mathrm{NO}_{2}$ and $\mathrm{SO}_{2}$ had positive correlations with $\mathrm{PM}_{2.5}$ and $\mathrm{PM}_{10}$. In addition, the $\mathrm{SO}_{2}$ correlation with $\mathrm{PM}_{2.5}$ and $\mathrm{PM}_{10}$ was better than that with $\mathrm{NO}_{2}$. This difference can be explained by the relative contribution of sulfate exceeding the nitrate in SIA which will be discussed later.

\section{Analysis of Chemical Components of PM2.5 during the G20 Period}

Previous studies have shown that within $\mathrm{PM}_{2.5}, \mathrm{NH}_{4}{ }^{+}$is mainly formed through $\mathrm{NH}_{3}$ gas-particle conversion; $\mathrm{SO}_{4}{ }^{2-}$ is mainly related to $\mathrm{H}_{2} \mathrm{SO}_{4}$, which is the result by the gasphase oxidation of $\mathrm{SO}_{2}$; and $\mathrm{NO}_{3}{ }^{-}$is related not only to the heterogeneous reaction of $\mathrm{HNO}_{3}$ but also to the heterogeneous hydrolysis of highly humid $\mathrm{N}_{2} \mathrm{O}_{5}$ (Riemer et al., 2003; Baek and Aneja, 2004; Chang et al., 2016). Fig. 5 compares the average concentrations of several $\mathrm{PM}_{2.5}$ components during the G20 period and the non-G20 period. The concentrations of all components (except for $\mathrm{Mg}^{2+}$ ) exhibited obvious decreases. Among them, $\mathrm{SO}_{4}{ }^{2-}$ showed the largest decline of $62.7 \%$, reflecting the effect of the "coal-reducing" measures during the $\mathrm{G} 20$ period. The decrease in $\mathrm{NO}_{3}{ }^{-}$was nearly $50 \%$, which reflected the combined effects of motor vehicle restrictions and the reduction of biofuel combustion from human sources and point sources. $\mathrm{Cl}^{-}$also exhibited a significant reduction, indicating the effect of the reduction of combustion emissions (Tao et al., 2017). The decreased concentrations of $\mathrm{Na}^{+}$and $\mathrm{Ca}^{2+}$ reflected the effect of dust control (Louie et al., 2005). $\mathrm{K}^{+}$is considered a tracer ion for biomass combustion (Wang et al., 2015). Notably, the decrease in the $\mathrm{NH}_{4}{ }^{+}$concentration was $61.89 \%$ during the $\mathrm{G} 20$ period, which exceeded the decreases in $\mathrm{NO}_{3}{ }^{-}$. It is reported that $\mathrm{NH}_{4}{ }^{+}$, $\mathrm{NO}_{3}{ }^{-}$, and $\mathrm{SO}_{4}{ }^{2-}$ form a buffer system, existing as $\left(\mathrm{NH}_{4}\right)_{2} \mathrm{SO}_{4}$ and $\mathrm{NH}_{4} \mathrm{NO}_{3}$ (Tao et al., 2012). And the $\mathrm{NH}_{4}{ }^{+}$concentration will not exceed those of nitrate and sulfate because the chemical activity of $\mathrm{NH}_{4}{ }^{+}$needs an acidic environment. Therefore, the possible reason for this may be that decreases in $\mathrm{SO}_{4}{ }^{2-}$ and $\mathrm{NO}_{3}{ }^{-}$lead to decreased $\mathrm{NH}_{4}{ }^{+}$concentrations.

Fig. 6 shows the proportions of sulfate, nitrate, and ammonia in $\mathrm{PM}_{2.5}\left(\rho\left(\mathrm{SNA} / \mathrm{PM}_{2.5}\right)\right)$, the sulfur oxidation ratio $\left(\mathrm{SOR}=\left[\mathrm{SO}_{4}{ }^{2-}\right] /\left[\mathrm{SO}_{2}+\mathrm{SO}_{4}{ }^{2-}\right]\right.$, the nitrogen oxidation ratio (NOR $=\left[\mathrm{NO}_{3}{ }^{-}\right] /\left[\mathrm{NO}_{\mathrm{x}}+\mathrm{NO}_{3}{ }^{-}\right]$), and the $\mathrm{PM}_{2.5}$ concentrations during the G20 period (Fig. 6(a)) and the non-G20 period (Fig. 6(b)). Higher SOR and NOR indicate increased formation of secondary aerosols in the atmosphere. During the G20 period, the average $\rho\left(\mathrm{SNA} / \mathrm{PM}_{2.5}\right)$ was $15 \%$, which was significantly lower than that during the non-G20 period (34\%). However, the SOR and NOR exhibited similar patterns in which they reached their minimum values in S2 and their maximum values in S3 during the G20 period. Sun et al. (2013) reported that RH has the most significant effect on $\mathrm{NO}_{3}{ }^{-}$and $\mathrm{SO}_{4}{ }^{2-}$ because higher $\mathrm{RH}$ can promote the formation of secondary inorganic ions in particles. The

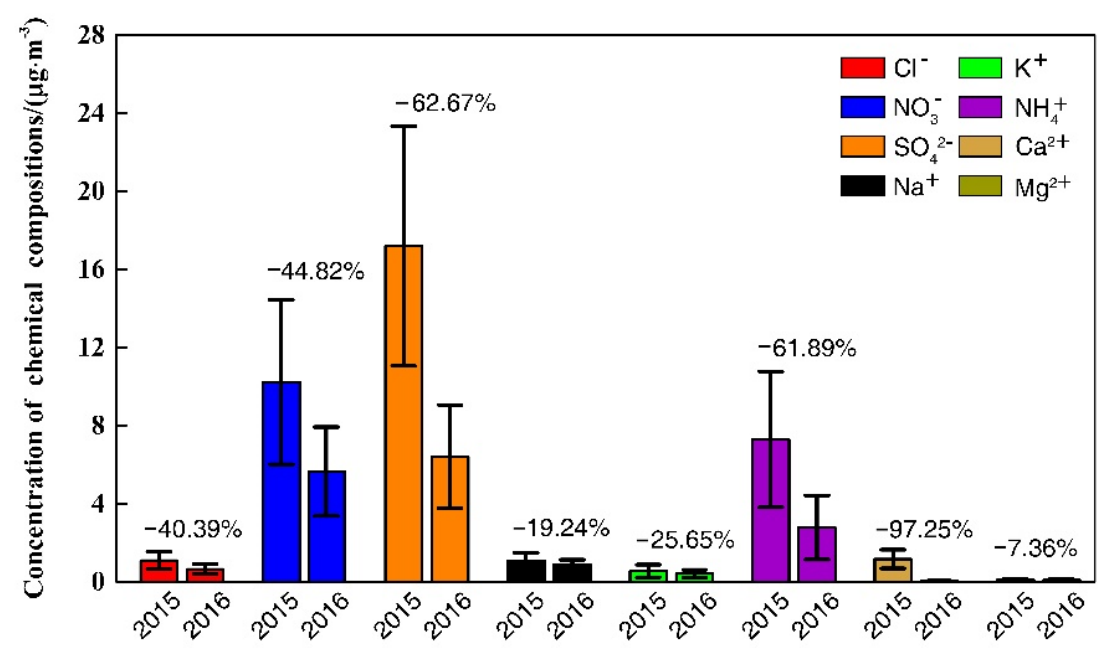

Fig. 5. Average concentration of $\mathrm{PM}_{2.5}$ chemical components during the G20 period (August 24-September 6, 2016) and the non-G20 period (August 24-September 6, 2015). 


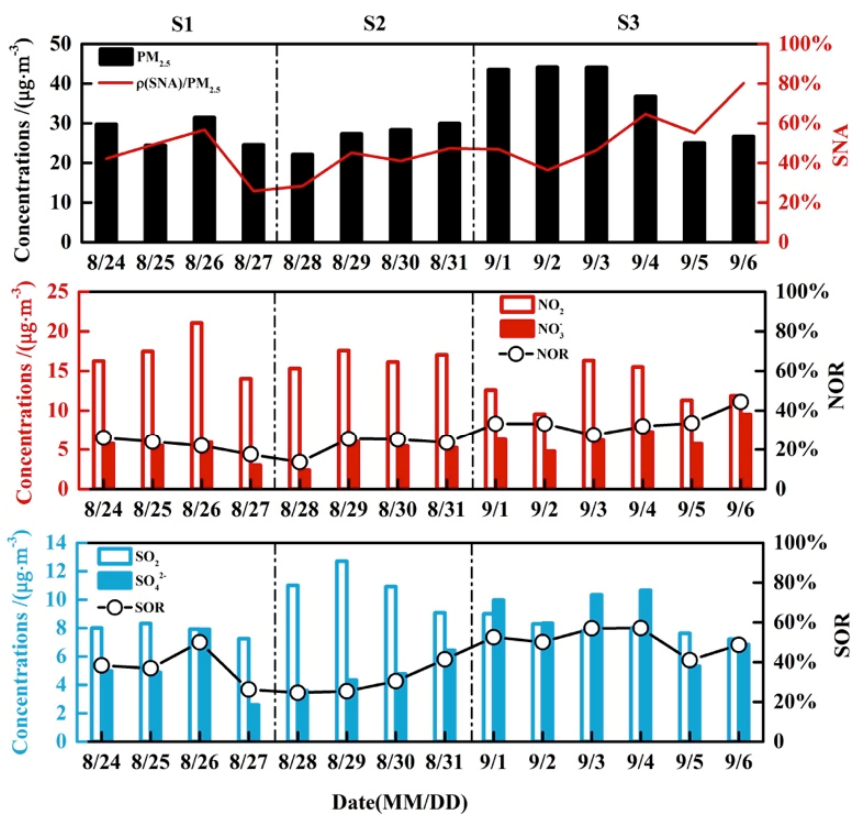

(a)

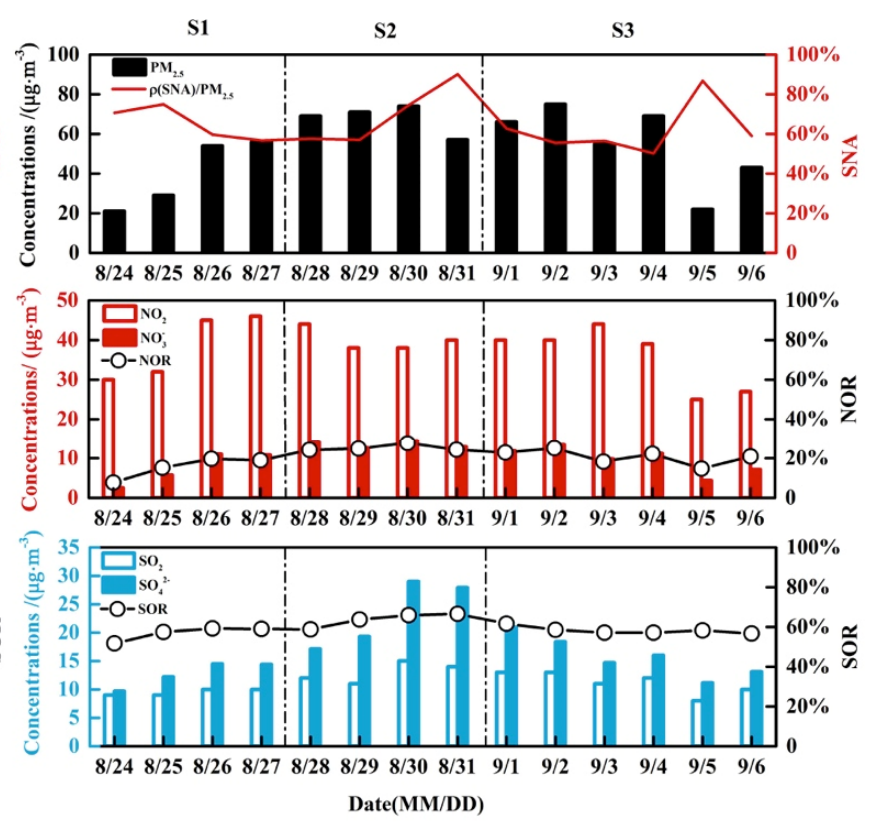

(b)

Fig. 6. Variations in sulfate, nitrate, and ammonia (SNA) in $\mathrm{PM}_{2.5}$; sulfur oxidation ratio (SOR); and nitrogen oxidation ratio (NOR) during (a) the G20 period (August 24-September 6, 2016) and (b) the non-G20 period (August 24-September 6, 2015).

average RH during S3 was $65 \%$, which was higher than that during S2 (only 48\%). Therefore, although the concentration of $\mathrm{SO}_{2}$ during $\mathrm{S} 2$ was similar to that during $\mathrm{S} 3$, the $\mathrm{SOR}$ and NOR were lowest in S2 and highest in S3.

Aw and Kleeman (2003) found that high $\mathrm{T}$ favors the volatilization of nitric acid and ammonia from the particulate phase of nitrate. As shown in Fig. 3, the T was similar during the G20 and non-G20 periods; thus, the NOR did not obviously change during the G20 and non-G20 periods. As for the variation of SOR, Liang et al. (2017) reported that the active photochemical oxidation could result in high $\mathrm{SO}_{2}-$ to-sulfate conversion rates. And the higher RH in summer can also favor the heterogeneous reaction of sulfate formation (as shown in Fig. 3). It is recognized that the SOR was significantly positively correlated with the RH but only slightly correlated with the T in Hangzhou (Wu et al., 2017). Hence, the variation of $\mathrm{RH}$ is the main reason for the change of SOR during different stages.

\section{Changes in Satellite $\mathrm{AOD}$ and $\mathrm{NO}_{2}$ Column during the G20 Period}

In Fig. 7, the variation of $\mathrm{AOD}$ and $\mathrm{NO}_{2}$ column over Hangzhou shows similar patterns to the air pollutants. In S3, the average AOD was 1.01, which decreased by $41 \%$ relative to $\mathrm{S} 1$ and decreased by $38 \%$ relative to $\mathrm{S} 2$. In $\mathrm{S} 3$, the average columnar $\mathrm{NO}_{2}$ was 10.1 molecules $\mathrm{cm}^{-2}$, which decreased by $30.3 \%$ relative to $\mathrm{S} 1$ and $\mathrm{S} 2$. This trend was consistent with the results of surface observations, which were discussed above.

\section{Analysis of the Spatial Evolution of Air Pollutants between Hangzhou and the Surrounding Cities}

Fig. 8 shows the pollutant concentrations of Hangzhou and the surrounding cities during the G20 period and nonG20 period. The decreases in $\mathrm{PM}_{2.5}, \mathrm{PM}_{10}$, and $\mathrm{CO}$ in the core area were the most prominent, followed by the strictly controlled area, with the controlled area being the least affected. The percentages by which the $\mathrm{PM}_{2.5}$ concentrations decreased in the three controlled areas from the non-G20 period to the $\mathrm{G} 20$ period were $42.64 \%, 30.25 \%$, and $6.92 \%$. However, the concentrations of $\mathrm{PM}_{10}$ and $\mathrm{CO}$ in the controlled area increased. The $\mathrm{SO}_{2}$ concentrations decreased by $38.07 \%$ and $40.79 \%$ in the core area and the strictly controlled area, respectively, while $\mathrm{SO}_{2}$ only decreased by $4.33 \%$ in the controlled area. The $\mathrm{NO}_{2}$ concentrations decreased by $43.30 \%$ in the core area and only decreased by $16.53 \%$ and $18.80 \%$ in the strictly controlled area and controlled area, respectively. Despite the increase in the $\mathrm{O}_{3}$ concentration in Hangzhou, the $\mathrm{O}_{3}$ concentration in the core area was essentially the same as that observed during the same period in 2015. In addition, the $\mathrm{O}_{3}$ concentration in the controlled area increased by $5.34 \%$ compared to that observed during the same period in 2015 .

\section{Comparison with Previous Studies}

By comparing the pollutant concentration during the G20 Summit with that during the Beijing APEC conference in 2014, the Beijing military parade in 2015 , and the Nanjing Youth Olympic Games in 2014, we found that the concentrations of $\mathrm{NO}_{2}, \mathrm{SO}_{2}, \mathrm{CO}, \mathrm{PM}_{2.5}$, and $\mathrm{PM}_{10}$ were reduced under the influence of emission reduction measures during these special events (as shown in Table S3). The $\mathrm{O}_{3}$ concentration decreased significantly during the military parade and the Nanjing Youth Olympic Games while the $\mathrm{O}_{3}$ concentration increased by $19 \%$ and $102 \%$ during the G20 Summit and APEC conference, respectively. This difference 

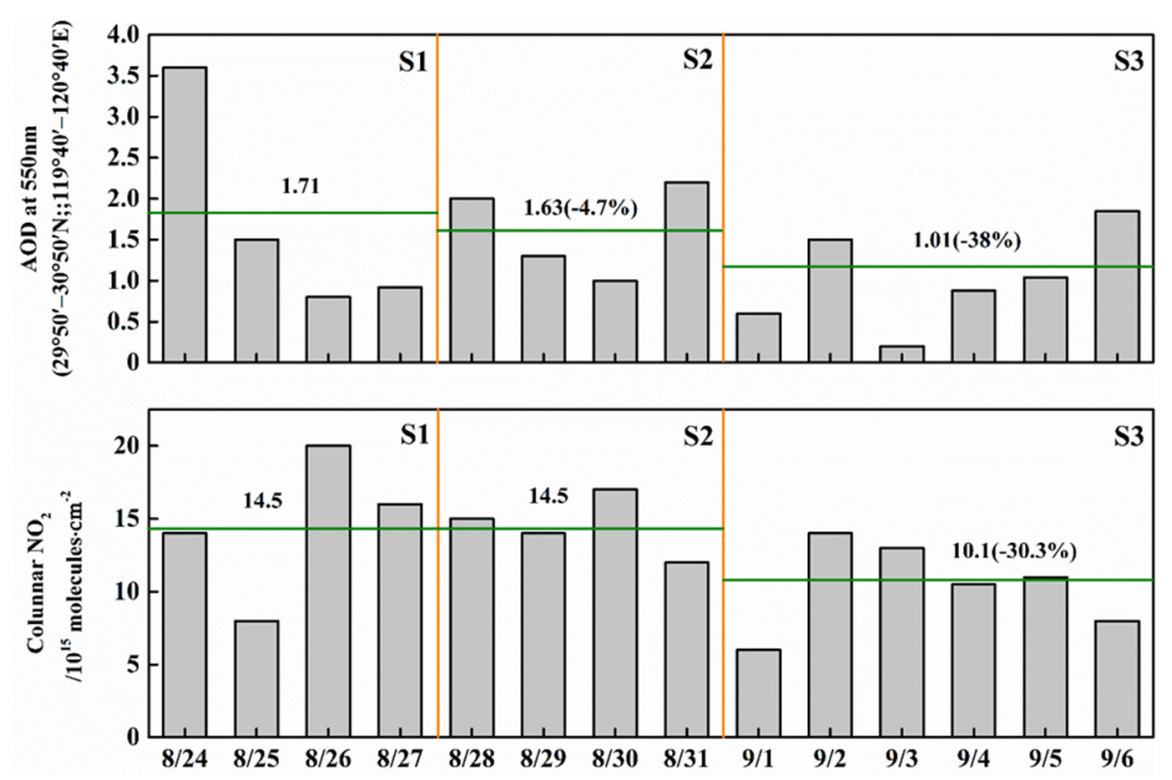

Fig. 7. Aerosol optical depth (AOD) derived from MODIS satellite data and columnar $\mathrm{NO}_{2}$ derived from OMI satellite data in the region of $29.5-30.5^{\circ} \mathrm{N}, 119.4-120.4^{\circ} \mathrm{E}$ in the $\mathrm{G} 20$ period. Green lines represent the average values of AOD and columnar $\mathrm{NO}_{2}$ during $\mathrm{S} 1, \mathrm{~S} 2$, and $\mathrm{S} 3$.

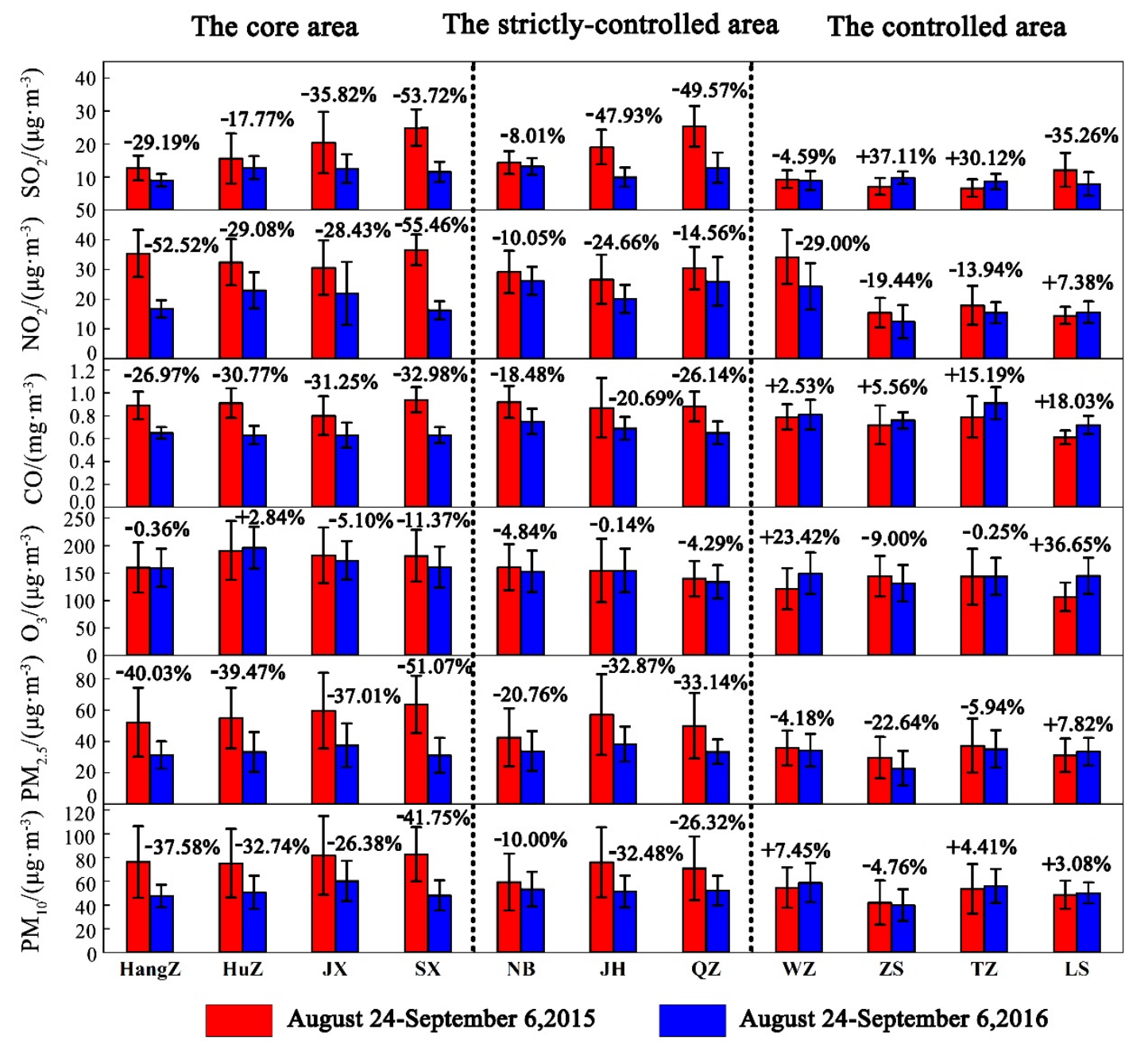

Fig. 8. Comparison of pollutant concentrations in Hangzhou and the surrounding cities during the G20 period (August 24September 6, 2016) and the non-G20 period (August 24-September 6, 2015). 
may be due to the large differences in meteorological conditions during the four important events and their different effects on $\mathrm{O}_{3}$ generation. Huang et al. (2017) analyzed the meteorological conditions during the 2014 Nanjing Youth Olympic Games. The results showed that the T during the Youth Olympic Games was lower than that in the same period in 2013, and there were more cloudy and rainy days. The low $\mathrm{T}$ and cloudy weather were not conducive to the formation of $\mathrm{O}_{3}$, and the $\mathrm{O}_{3}$ concentration clearly decreased. Wang et al. (2017b) analyzed the Beijing military parade in 2015 and maintained that the continuous low $\mathrm{T}$ during the parade had an important contribution to the reduction in the $\mathrm{O}_{3}$ concentration. We found that the average $\mathrm{T}$ during the G20 Summit reached $31^{\circ} \mathrm{C}$, which is conducive to the large BVOC emissions and enhanced photochemical reactions.

The aforementioned differences during the four events may be due to a lack of sufficient consideration of the $\mathrm{O}_{3}$ sensitivity pattern during the implementation of emission reduction measures. Previous studies have shown that the $\mathrm{O}_{3}$ sensitivity patterns in Beijing, Nanjing, and Hangzhou are VOCs-limited (Tang et al., 2012; An et al., 2015; Li et al., 2017). For these areas, if $\mathrm{NO}_{\mathrm{x}}$ emission control measures are stronger than the VOC emission control measures, the inhibitory effect of $\mathrm{NO}_{\mathrm{x}}$ on $\mathrm{O}_{3}$ production will be weak, and the $\mathrm{O}_{3}$ concentration will increase significantly. Wang et al. (2015) found that the regional VOC reduction during the APEC conference was significantly less than that of $\mathrm{NO}_{\mathrm{x}}$, while the regional VOC reduction during the parade was significantly higher than that of $\mathrm{NO}_{\mathrm{x}}$, which increased the $\mathrm{O}_{3}$ concentration during the APEC conference and decreased the $\mathrm{O}_{3}$ concentration during the parade. Ding et al. (2015) further verified this conclusion by estimating the $\mathrm{NO}_{\mathrm{x}}$ emission reduction during the 2014 Nanjing Youth Olympic Games. Because this research did not synchronize VOCs and the Zhejiang provincial government did not publish the specific emission reduction plan and implementation strength during the $\mathrm{G} 20$ period, the reason for the increase in $\mathrm{O}_{3}$ concentration during the $\mathrm{G} 20$ Summit requires further investigation.

\section{CONCLUSIONS}

In this study, the variations in the air pollutant characteristics and their corresponding meteorological conditions in Hangzhou and its surrounding areas during the G20 period (August 24-September 6, 2016) were analyzed and compared to those observed during the same dates for the five previous years. The RH was lower during the G20 period than the preceding years, whereas the other meteorological conditions were similar to their average levels. Furthermore, compared to the three previous years, the majority of the studied air pollutants were significantly reduced, with the average daily concentrations for $\mathrm{SO}_{2}, \mathrm{NO}_{2}, \mathrm{PM}_{2.5}$, and $\mathrm{PM}_{10}$ decreasing by $42.6 \%, 57.1 \%, 38.5 \%$, and $36 \%$, respectively; the $\mathrm{O}_{3}$ concentration, however, significantly increased (by $19 \%$ ). In addition, the concentrations of most of the chemical components of $\mathrm{PM}_{2.5}$ decreased, with sulfate and nitrate exhibiting the largest reductions. The AOD and the columnar $\mathrm{NO}_{2}$ in the region of $29.5-30.5^{\circ} \mathrm{N}$ and $119.4-120.4^{\circ} \mathrm{E}$ during the G20 period also displayed a trend similar to that of the observed surface pollutant concentrations.

Based on our comprehensive results and observational analysis, emission reduction measures implemented on the regional scale effectively improved the air quality during the G20 period, suggesting that regional jointly emission reduction are ideal for controlling air pollution in megacities such as Hangzhou, and even the entire YRD region. Moreover, the effects of $\mathrm{O}_{3}-\mathrm{VOCs}-\mathrm{NO}_{\mathrm{x}}$ sensitivity must be fully considered, particularly for VOCs-limited cities, e.g., Hangzhou; specifically, to prevent a significant increase in $\mathrm{O}_{3}$, emission control measures should ensure that the reduction in VOCs exceeds that of $\mathrm{NO}_{\mathrm{x}}$. Finally, collaborative efforts in pollutant emission and control between adjacent regions should be intensified a few days in advance-before the occurrence of adverse weather conditions - to maintain low pollutant concentrations during major events. The strategies implemented during the G20 Summit can be used as a reference when devising air quality improvement measures for similar activities in the future.

\section{ACKNOWLEDGMENTS}

This study was supported by the National Key Research and Development Program of China (No. 2018YFC0214001), the Major Research Plan of the National Natural Science Foundation of China (No. 91644226), the Major Science And Technology Project of Sichuan (No. 2018SZDZX0023), the Key Science and Technology Plan Project of Sichuan (No. 2018JY0011), the Key Project of Science Foundation of Education Department of Sichuan (18ZA0086), and the Scientific Research Foundation of Chengdu University of Information Technology (KYTZ201725). We thank the editor and reviewers for their valuable comments. The meteorological data set was provided by the China Meteorological Data Sharing Service System (http://cdc.cma.gov.cn). Additionally, the air pollutant data were downloaded from the National Urban Air Quality Real-time Publishing Platform (http://106. 37.208.233:20035/). The data of MODIS AOD Level 3 products in 2016 were obtained from https://modis.gsfc.nasa. gov/, which is maintained by NASA. The NCEP Global Forecast System (GFS) analysis data were obtained from https://www.ncdc.noaa.gov/data-access, which is maintained by the National Centers for Environmental Information. All data are available from the corresponding author upon request.

\section{DISCLAIMER}

The authors declare that they have no conflicts of interest.

\section{SUPPLEMENTARY MATERIAL}

Supplementary data associated with this article can be found in the online version at http://www.aaqr.org.

\section{REFERENCES}

An, J., Zou, J., Wang, J., Lin, X. and Zhu, B. (2015). 
Differences in ozone photochemical characteristics between the megacity Nanjing and its suburban surroundings, Yangtze river delta, China. Environ. Sci. Pollut. Res. Int. 22: 19607-19617.

Aw, J. and Kleeman, M.J. (2003). Evaluating the first-order effect of interannual temperature variability on urban air pollution. J. Geophys. Res. Atmos. 108: 4365.

Baek, B.H. and Aneja, V.P. (2004). Measurement and analysis of the relationship between ammonia, acid gases, and fine particles in eastern North Carolina. J. Air Waste Manage. Assoc. 54: 623-633.

Chan, C.K. and Yao, X. (2008). Air pollution in mega cities in China. Atmos. Environ. 42: 1-42.

Chang, W.L., Brown, S.S., Stutz, J., Middlebrook, A.M., Bahreini, R., Wagner, N.L., Dubé, W.P., Pollack, I.B., Ryerson, T.B. and Riemer, N. (2016). Evaluating $\mathrm{N}_{2} \mathrm{O}_{5}$ heterogeneous hydrolysis parameterizations for CalNex 2010. J. Geophys. Res. Atmos. 121: 5051-5070.

Cohen, A.J., Brauer, M., Burnett, R., Anderson, H.R., Frostad, J., Estep, K., Balakrishnan, K., Brunekreef, B., Dandona, L., Dandona, R., Feigin, V., Freedman, G., Hubbell, B., Jobling, A., Kan, H., Knibbs, L., Liu, Y., Martin, R., Morawska, L., Pope, C.A., III, Shin, H., Straif, K., Shaddick, G., Thomas, M., van Dingenen, R., van Donkelaar, A., Vos, T., Murray, C.J.L. and Forouzanfar, M.H. (2017). Estimates and 25-year trends of the global burden of disease attributable to ambient air pollution: an analysis of data from the Global Burden of Diseases Study 2015. Lancet 389: 1907-1918.

Ding, J., van der A, R.J., Mijling, B., Levelt, P.F. and Hao, N. (2015). $\mathrm{NO}_{\mathrm{x}}$ emission estimates during the 2014 Youth Olympic Games in Nanjing. Atmos. Chem. Phys. 15: 9399-9412.

Dong, X., Gao, Y., Fu, J.S., Li, J., Huang, K., Zhuang, G. and Zhou, Y. (2013). Probe into gaseous pollution and assessment of air quality benefit under sector dependent emission control strategies over megacities in Yangtze River Delta, China. Atmos. Environ. 79: 841-852.

Feng, R., Wang, Q., Huang, C.C., Liang, J., Luo, K., Fan, J.R. and Cen, K.F. (2019). Investigation on air pollution control strategy in Hangzhou for post-G20/pre-Asiangames period (2018-2020). Atmos. Pollut. Res. 10: 197208.

Geng, F., Tie, X., Guenther, A., Li, G., Cao, J. and Harley, P. (2011). Effect of isoprene emissions from major forests on ozone formation in the city of Shanghai, China. Atmos. Chem. Phys. 11: 10449-10459.

$\mathrm{Hu}$, J., Chen, J., Ying, Q. and Zhang, H. (2016). One-year simulation of ozone and particulate matter in China using WRF/CMAQ modeling system. Atmos. Chem. Phys. 16: 10333-10350.

Hu, J., Li, X., Huang, L., Ying, Q., Zhang, Q., Zhao, B., Wang, S. and Zhang, H. (2017). Ensemble prediction of air quality using the WRF/CMAQ model system for health effect studies in China. Atmos. Chem. Phys. 17: 13103-13118.

Huang, Q., Wang, T., Chen, P., Huang, X., Zhu, J. and Zhuang, B. (2017). Impacts of emission reduction and meteorological conditions on air quality improvement during the 2014 Youth Olympic Games in Nanjing, China. Atmos. Chem. Phys. 17: 13457-13471.

Jansen, R.C., Shi, Y., Chen, J., Hu, Y., Xu, C., Hong, S., Li, J. and Zhang, M. (2014). Using hourly measurements to explore the role of secondary inorganic aerosol in $\mathrm{PM}_{2.5}$ during haze and fog in Hangzhou, China. Adv. Atmos. Sci. 31: 1427-1434.

Ji, Y., Qin, X., Wang, B., Xu, J., Shen, J., Chen, J., Huang, K., Deng, C., Yan, R., Xu, K. and Zhang, T. (2018). Counteractive effects of regional transport and emission control on the formation of fine particles: A case study during the Hangzhou G20 summit. Atmos. Chem. Phys. 18: 13581-13600.

Jin, X. and Holloway, T. (2015). Spatial and temporal variability of ozone sensitivity over China observed from the ozone monitoring instrument. J. Geophys. Res. Atmos. 120: 7229-7246.

Li, K., Chen, L., Ying, F., White, S.J., Jang, C., Wu, X., Gao, X., Hong, S., Shen, J., Azzi, M. and Cen, K. (2017). Meteorological and chemical impacts on ozone formation: A case study in Hangzhou, China. Atmos. Res. 196: 40-52.

Li, K., Chen, L., White, S.J., Zheng, X., Lv, B., Lin, C., Bao, Z., Wu, X., Gao, X., Ying, F., Shen, J., Azzi, M. and Cen, K. (2018). Chemical characteristics and sources of $\mathrm{PM}_{1}$ during the 2016 summer in Hangzhou. Environ. Pollut. 232: 42-54.

Liang, P., Zhu, T., Fang, Y., Li, Y., Han, Y., Wu, Y., Hu, M. and Wang, J. (2017). The role of meteorological conditions and pollution control strategies in reducing air pollution in Beijing during APEC 2014 and Victory Parade 2015. Atmos. Chem. Phys. 17: 13921-13940.

Liu, H., Ma, W., Qian, J., Cai, J., Ye, X., Li, J. and Wang, X. (2015). Effect of urbanization on the urban meteorology and air pollution in Hangzhou. J. Meteorol. Res. 29: 950965.

Liu, Y., Li, L, An, J., Huang, L., Yan, R., Huang, C., Wang, H., Wang, Q. Wang, M. and Zhang, W. (2018). Estimation of biogenic VOC emissions and its impact on ozone formation over the Yangtze River Delta region, China. Atmos. Environ. 186: 113-128.

Louie, P.K., Chow, J.C., Chen, L.W., Watson, J.G., Leung, G. and Sin, D.W. (2005). $\mathrm{PM}_{2.5}$ chemical composition in Hong Kong: Urban and regional variations. Sci. Total Environ. 338: 267-281.

Ni, Z.Z., Luo, K., Gao, X., Gao, Y., Fan, J.R., Fu, J.S. and Chen, C.H. (2019). Exploring the stratospheric source of ozone pollution over China during the 2016 Group of Twenty summit. Atmos. Pollut. Res. 10: 1267-1275.

Quan, J. and Zhang, X. (2008). Assessing the role of ammonia in sulfur transformation and deposition in China. Atmos. Res. 88: 78-88.

Riemer, N., Vogel, H., Vogel, B., Schell, B., Ackermann, I., Kessler, C. and Hass, H. (2003). Impact of the heterogeneous hydrolysis of $\mathrm{N}_{2} \mathrm{O}_{5}$ on chemistry and nitrate aerosol formation in the lower troposphere under photosmog conditions. J. Geophys. Res. Atmos. 108: 291302.

Situ, S., Wang, X., Guenther, A., Zhang, Y., Wang, X., 
Huang, M., Fan, Q. and Xiong, Z. (2014). Uncertainties of isoprene emissions in the MEGAN model estimated for a coniferous and broad-leaved mixed forest in Southern China. Atmos. Environ. 98: 105-110.

Su, W., Liu, C., Hu, Q., Fan, G., Xie, Z., Huang, X., Zhang, T., Chen, Z., Dong, Y., Ji, X., Liu, H., Wang, Z. and Liu, J. (2017). Characterization of ozone in the lower troposphere during the 2016 G20 conference in Hangzhou. Sci. Rep. 7: 17368.

Sun, Y., Wang, Z., Fu, P., Jiang, Q., Yang, T., Li, J. and Ge, $X$. (2013). The impact of relative humidity on aerosol composition and evolution processes during wintertime in Beijing, China. Atmos. Environ. 77: 927-934.

Tang, G., Wang, Y., Li, X., Ji, D., Hsu, S. and Gao, X. (2012). Spatial-temporal variations in surface ozone in Northern China as observed during 2009-2010 and possible implications for future air quality control strategies. Atmos. Chem. Phys. 12: 2757-2776.

Tao, J., Shen, Z., Zhu, C., Yue, J., Cao, J., Liu, S., Zhu, L. and Zhang, R. (2012). Seasonal variations and chemical characteristics of sub-micrometer particles $\left(\mathrm{PM}_{1}\right)$ in Guangzhou, China. Atmos. Res. 118: 222-231.

Tao, J., Zhang, L., Cao, J. and Zhang, R. (2017). A review of current knowledge concerning $\mathrm{PM}_{2.5}$ chemical composition, aerosol optical properties and their relationships across China. Atmos. Chem. Phys. 17: 9485-9518.

Wang, T., Xue, L., Brimblecombe, P., Lam, Y.F., Li, L. and Zhang, L. (2017a). Ozone pollution in China: A review of concentrations, meteorological influences, chemical precursors, and effects. Sci. Total Environ. 575: 15821596.

Wang, Z., Li, Y., Chen, T., Li, L., Liu, B., Zhang, D., Sun, F., Wei, Q., Jiang, L. and Pan, L. (2015). Changes in atmospheric composition during the 2014 APEC conference in Beijing. J. Geophys. Res. Atmos. 120: 12695-12707.

Wang, Z.S., Li, Y.T., Zhang, D.W., Chen, T., Wei, Q., Sun, T.H., Wang, B.Y., Pan, J.X., Cui, J.X. and Pi, S. (2017b). Analysis on air quality in Beijing during the military parade period in 2015. China Environ. Sci. 37: 1628-1636.
Wu, D., Lin, S.L., Yang, H.Q., Du, R.G., Xia, J.R., Qi, B., Liu, G., Li, F.Y., Yang, M. and Gai, X.L. (2017). Pollution characteristics and light extinction contribution of water-soluble ions of $\mathrm{PM}_{2.5}$ in Hangzhou. Environ. Sci. 38: 2656-2666.

Wu, K., Yang, X., Chen, D., Gu, S., Lu, Y., Jiang, Q., Wang, K., Ou, Y., Qian, Y., Shao, P. and Lu, S. (2020). Estimation of biogenic VOC emissions and their corresponding impact on ozone and secondary organic aerosol formation in China. Atmos. Res. 231: 104656.

Xing, J., Wang, S.X., Jang, C., Zhu, Y. and Hao, J.M. (2011). Nonlinear response of ozone to precursor emission changes in China: A modeling study using response surface methodology. Atmos. Chem. Phys. 11: 5027-5044.

Xu, Y., Ying, Q., Hu, J., Gao, Y., Yang, Y., Wang, D. and Zhang, H. (2018). Spatial and temporal variations in criteria air pollutants in three typical terrain regions in Shaanxi, China, during 2015. Air Qual. Atmos. Health 11: 95-109.

Yan, R.S., Li, L., An, J.Y., Lu, Q., Wang, S., Zhu, Y., Jang, C.J. and Fu, J.S. (2016). Establishment and application of nonlinear response surface model of ozone in the Yangtze river delta region during summertime. Acta Sci. Circumstant. 36: 1383-1392.

Yarwood, G., Emery, C., Jung, J., Nopmongcol, U. and Sakulyanontvittaya, T. (2013). A method to represent ozone response to large changes in precursor emissions using high-order sensitivity analysis in photochemical models. Geosci. Model Dev. 6: 1601-1608.

Zhang, G., Xu, H., Qi, B., Du, R., Gui, K., Wang, H., Jiang, W., Liang, L. and Xu, W. (2018). Characterization of atmospheric trace gases and particulate matter in Hangzhou, China. Atmos. Chem. Phys. 18: 1705-1728.

Received for review, April 26, 2019 Revised, September 21, 2019 Accepted, September 22, 2019 